\title{
Magnetic resonance imaging for assessing hamstring injuries: clinical benefits and pitfalls - a review of the current literature
}

This article was published in the following Dove Press journal:

Open Access Journal of Sports Medicine

17 July 2017

Number of times this article has been viewed

\section{Max Greenky \\ Steven B Cohen}

Department of Orthopedic Surgery, Rothman Institute, Thomas Jefferson University, Philadelphia, PA, USA
Correspondence: Steven B Cohen Sports Medicine Research, Department of Orthopedic Surgery, Rothman Institute, Thomas Jefferson University, 925 Chestnut Street, Philadelphia, PA 19107, USA

Tel +I 2673397812

Fax +l 2155030580

Email steven.cohen@rothmaninstitute. com

\begin{abstract}
Hamstring injuries are common injuries in all levels of athletics. Hamstring injuries can cause prolonged absence from sports and have a notorious rate of reinjury. Magnetic resonance imaging (MRI) is being increasingly utilized following a hamstring injury. Physicians are being increasingly asked to utilize MRI to predict clinical outcomes, including time frame for return to play and risk of reinjury. In spite of numerous studies in this area, no clear consensus exists. The purpose of this paper is to summarize the literature and evidence regarding the role of MRI in treating hamstring injuries.
\end{abstract}

Keywords: hamstring injury, MRI, return to play

\section{Introduction}

Hamstring injuries are common injuries in professional, collegiate, high school, and recreational athletes. Hamstring injuries are typically caused by damage to the myotendinous unit, either proximally or distally. Unfortunately, hamstring injuries can cause a prolonged absence from sports and have a high incidence of reinjury upon returning to participation in sports. ${ }^{1,2,21}$ After a hamstring injury has occurred, one of the first inquiries from athletes, coaches, and family members is when they can expect return to play (RTP). While hamstring injuries are generally a clinical diagnosis, magnetic resonance imaging (MRI) has become increasingly available and utilized following hamstring injury. ${ }^{3}$ This is especially true in the realm of collegiate and professional athletes. MRI allows the clinician to obtain detailed information regarding the injury in terms of specific anatomic location, number of tendons and muscles involved, crosssectional area involved, and extent of the tear. With this in mind, sport physicians and radiologists are being increasingly asked to use MRI findings and characteristics to predict clinical outcomes. Specifically, clinicians are being asked time frames for RTP and risk of reinjury based on the findings of MRI studies. In spite of numerous studies being devoted to this area of research, there has been no clear consensus obtained regarding the utility of MRI in overall care in hamstring injuries.

The purpose of this manuscript is to help outline the utility of MRI to the clinician in hamstring injuries. Specifically, this manuscript will attempt to highlight the role of MRI in diagnosing hamstring injuries, review the literature regarding MRI findings and predicting RTP, and summarize the evidence of MRI findings for predicting risk of reinjury. The authors reviewed the available literature by conducting a PubMed literature search using the terms "hamstring injury", "hamstring strain", "magnetic resonance imaging", "MRI", "return to play", "and hamstring re-injury". References 
for each of the articles were also reviewed to find all available resources.

\section{MRI in the diagnosis of hamstring injuries}

Although hamstring injuries can often be diagnosed using clinical criteria, including history and physical exam, MRI is being increasingly utilized. An MRI should however be routinely obtained in the case of acute proximal hamstring injuries, in order to rule out an avulsion injury from the proximal attachment of the hamstrings to the ischial tuberosity. Numerous studies have proven the successful surgical treatment of these injuries to be superior to nonoperative treatment. Surgical treatment of proximal hamstring-avulsion injuries is associated with increased patient satisfaction, superior rates of preinjury-activity level of sport, and increased hamstring-muscle strength. ${ }^{4,522}$ Further, these injuries have superior outcomes if they are managed earlier in their course. ${ }^{6-8}$

MRI is useful in determining multiple characteristics or hamstring injuries, including the size and extent of the injury (length and volume), the specific muscle involved (semitendinosus, semimembranosus, and/or biceps femoris - short and long head), the location of the injury (proximal versus distal injuries and muscle-belly injury versus musculotendinous injuries versus intratendinous injuries), and the signal intensity of injuries. ${ }^{20}$

\section{MRI findings and RTP}

While hamstring injuries are typically reliably diagnosed using clinical evaluations, there are numerous studies that have found clinical evaluation not to be a reliable tool to predict RTP or reinjury. ${ }^{9,10}$ There have been several studies done regarding findings on MRI and correlation with RTP. ${ }^{5,11-18}$ This is especially true in the arena of professional athletics. The findings of these studies are conflicting.

\section{Evidence for MRI findings predicting RTP}

Numerous attempts have been made to correlate MRI findings with RTP. In 2012, Ekstrand et al conducted a study among 516 hamstring injuries in professional soccer players. ${ }^{14}$ The study found that time to RTP increased as MRI-severity grade increased. An additional study in 2016 by Svensson et al evaluated MRI findings in professional soccer players and attempted to correlate these with RTP. ${ }^{16}$ The study found that radiological grade and size of the injury directly correlated with RTP; however, location and muscle involved did not.
In a prospective study of hamstring injuries in Australian rules football, Gibbs et al examined the MRI findings of 31 consecutive hamstring injuries diagnosed clinically. ${ }^{23}$ Positive MRI findings versus those with no abnormal findings were associated with longer RTP. Further, the length of the strain found on MRI correlated with longer time to RTP. Of note, absence of MRI findings on clinically diagnosed acute hamstring injuries was a positive predictor for quicker RTP.

Several attempts have been made to develop grading systems using MRI findings to predict RTP. In a retrospective review of MRI findings, Pollock et al evaluated the British Athletics muscle-injury classification, a system that grades hamstring injuries on a scale of $0-4$, and specified location

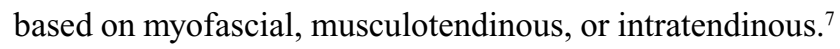
The authors found that each of the different grades was associated with increased RTP time. They also found that intratendinous injuries were associated with a higher reinjury rate.

Cohen et al examined 43 hamstring injuries in 38 professional American football players and correlated findings on MRI with RTP. ${ }^{5}$ A novel grading system developed to include age of player, number of muscles involved, location of injury, percentage of muscle/tendon involved, degree of retraction, and length of $T_{2}$-signal intensity was utilized. The study found that prolonged recovery (defined as more than two or three games missed) was associated with multiple-muscle injury, injuries distal in the muscle belly, short head of biceps femoris injury, grade III radiologic strain, greater than $75 \%$ muscle involvement, greater than $2 \mathrm{~cm}$ of retraction, and circumferential muscle edema. In terms of the novel scoring system, the authors found rapid RTP was more likely with a score of less than 10. This study did not assess the relationship between MRI findings and risk of reinjury. Hamilton et al evaluated the clinical relevance of Cohen et al's grading system by applying it to their prospectively collected study on MRI findings and hamstring injuries in professional soccer players. ${ }^{13}$ In this study, Hamilton et al found Cohen et al's grading system to be unreliable in predicting RTP.

\section{Evidence against using MRI findings to predict RTP}

Several studies in the literature have found that MRI findings did not predict RTP more accurately than clinical evaluation. In a study of 74 nonprofessional athletes with MRI-confirmed hamstring injuries, Moen et al examined clinical and MRI parameters to predict RTP using both univariate and multivariate analysis. ${ }^{24}$ The study found that athlete-predicted RTP and passive straight-leg-raise deficit were associated with prolonged RTP. MRI grading was not associated with predicting RTP. 
Reurink et al conducted a systematic review regarding MRI findings and RTP prognosis. ${ }^{15}$ Interestingly, they found that MRI images without hypersensitivity on fluid-sensitive sequences were associated with shorter time to RTP, and proximal free-tendon involvement was associated with increased time to RTP. Evidence regarding other variables showed no association or conflicting outcomes. They also noted that there was a lack of high-quality studies without methodological or bias limitations.

Svensson et al performed an additional systematic review of the literature regarding MRI characteristics of hamstring imaging and correlation with RTP. ${ }^{16}$ The authors found that there was an association with size of the hamstring injury on MRI and increased time to RTP.

Wangensteen et al performed a study that assessed the added value of MRI findings to patient history and clinical examination..$^{20}$ The authors found that they were able to explain $29 \%$ of variance in time to RTP with clinical factors and history alone utilizing pain scores, length of hamstring tenderness, forced stop from participation in sport, and painful resisted-knee flexion. When MRI was added to the model, only an additional $2.8 \%$ of variance was explained.

\section{Predicting reinjury}

Unfortunately, reinjury is extremely common following hamstring injury, and can be as high as $34 \% .{ }^{19-23}$ Further, reinjury is associated with more severe symptoms and prolonged recovery time. ${ }^{1,2}$ Currently, RTP is guided by clinical judgment. While there is no consensus on clinical criteria for RTP, several studies have suggested that athlete are ready for RTP when they can exhibit painless full range of motion, full strength, and the ability to perform asymptomatic sport-specific activities. ${ }^{19}$ Numerous studies have sought to identify risks for reinjury in order to modify these risks or delay RTP. ${ }^{21,23}$ With this in mind, investigators have focused on using MRI findings at the time of injury or during recovery to predict safe RTP.

In a systematic review, de Visser et al looked at risk factors for hamstring re-injury. ${ }^{17}$ In addition to previous anterior cruciate ligament-reconstruction surgery, larger initial injury volume on MRI was associated with an increased risk of reinjury. Koulouris et al looked at MRI parameters and other characteristics in professional Australian Football players at time of injury and association with reinjury. ${ }^{21}$ The only factor that was statistically significant was a history of anterior cruciate ligament tear. Length of hamstring-tendon injury was longer in those who acquired a reinjury; however, this did not reach statistical significance, likely secondary to being underpowered. de Vos et al studied the effect of clinical findings and MRI findings in reinjury in 64 patients with acute hamstring injuries. ${ }^{11}$ Such clinical findings as number of prior hamstring injuries, knee-extension deficit, decrease in knee-flexion force, and localized palpation discomfort following injury were associated with increased reinjury rate. MRI findings were not associated with reinjury.

Reurink et al also conducted a study examining MRI at the time athletes were clinically cleared for RTP. In this study, $89 \%$ of athletes showed MRI abnormalities on RTP; however, only five of 53 had a reinjury. This indicates that normalization of MRI findings is not required for RTP. Interestingly, in a third of athletes returning to play, MRI findings showed newly formed fibrous scar tissue. The clinical relevance of this is not evident from the study, however. ${ }^{25}$ In a later study, Reurink et al confirmed that fibrosis on MRI at RTP is not associated with risk of reinjury. ${ }^{26}$

In a systematic review, van Heumen et al evaluated MRI findings as prognostic factors for reinjury. ${ }^{12}$ The study found that there was no strong evidence for any MRI findings as prognosticators for reinjury, however, intratendinous injuries and injuries to the biceps femoris were moderately associated with reinjury.

\section{Conclusion}

The role of MRI in the diagnosis and management of acute hamstring injury continues to expand, particularly in elitelevel athletes who require early return to sport. There is proven value in getting an MRI in the acute setting to identify avulsion injuries of the ischial tuberosity or distal injuries about the knee, and thus determine if an injury is appropriate for operative intervention. In the current literature, there is evidence of MRI-grading systems and characteristics for predicting a time frame for RTP. Unfortunately, there is less evidence regarding the prognostic value of MRI in predicting reinjury. Additional prospective work is needed to identify the utility of predicting RTP and the risk of reinjury.

\section{Disclosure}

The authors report no conflicts of interest in this work.

\section{References}

1. Orchard J, Seward H. Injury report 2009: Australian Football League. Sport Health. 2010;28:10-19.

2. Woods C, Hawkins R, Maltby S, Hulse M, Thomas A, Hodson A. The Football Association Medical Research Programme: an audit of injuries in professional football - analysis of hamstring injuries. $\mathrm{Br} J$ Sports Med. 2004;38:36-41.

3. Thompson S, Fung S, Wood D. The prevalence of proximal hamstring pathology on MRI in the asymptomatic population. Knee Surg Sports Traumatol Arthrosc. 2017;25:108-111. 
4. Subbu R, Benjamin-Laing H, Haddad F. Timing of surgery for complete proximal hamstring avulsion injuries: successful clinical outcomes at 6 weeks, 6 months, and after 6 months of injury. Am J Sports Med. 2015;43: 385-391.

5. Cohen S, Rangavajulla A, Vyas D, Bradley J. Functional results and outcomes after repair of proximal hamstring avulsions. Am J Sports Med. 2012;40:2092-2098.

6. Askling CM, Koulouris G, Saartok T, Werner S, Best TM. Total proximal hamstring ruptures: clinical and MRI aspects including guidelines for postoperative rehabilitation. Knee Surg Sports Traumatol Arthrosc. 2013;21:515-533.

7. Pollock N, Patel A, Chakraverty J, Suokas A, James S, Chakraverty R. Time to return to full training is delayed and recurrence rate is higher in intratendinous acute hamstring injury in elite track and field athletes: clinical application of the British Athletics muscle injury classification. Br J Sports Med. 2016;50:305-310.

8. Reurink G, Almousa E, Goudswaard G, et al. No association between fibrosis on magnetic resonance imaging at return to play and hamstring re-injury risk. Am J Sports Med. 2015;43:1228-1234.

9. Schut L, Wangensteen A, Maaskant J, Tol J, Bahr R, Moen M. Can clinical evaluation predict return to sport after acute hamstring injuries? Sports Med. 2017;47:1123-1144.

10. van der Horst N, van de Hoef S, Reurink G, Huissetede B, Backx F. Return to play after hamstring injuries: a qualitative systematic review of definitions and criteria. Sports Med. 2016;46:899-912.

11. de Vos R, Reurink G, Goudswaard G, Moen MH, Weir A, Tol JL. Clinical findings just after return to play predict hamstring re-injury, but baseline MRI findings do not. Br J Sports Med. 2014;48:1877-1884.

12. van Heumen M, Tol J, de Vos R, et al. The prognostic value of MRI in determining re-injury risk following acute hamstring injury: a systematic review. Br J Sports Med. Epub 2017 March 4.

13. Hamilton B, Wangensteen A, Whiteley R, et al. Cohen's MRI scoring system has limited value in predicting return to play. Knee Surg Sports Traumatol Arthrosc. Epub 2017 Feb 4.

14. Ekstrand J, Healy J, Waldén M, et al. Hamstring muscle injuries in professional football: the correlation of MRI findings with return to play. Br J Sports Med. 2012;46:112-117.
15. Reurink G, Brilman E, de Vos R, et al. Magnetic resonance imaging in acute hamstring injury: can we provide a return to play prognosis? Sports Med. 2015;45:133-146.

16. Svensson K, Alricsson M, Eckerman M, Magounakis T, Werner S. The correlation between the imaging characteristics of hamstring injuries and time required before returning to sports: a literature review. J Exerc Rehabil. 2016;12:134-142.

17. de Visser H, Reijman m, Heijboer M, Bos P. Risk factors of recurrent hamstring injuries: a systematic review. Br J Sports Med. 2012;46: 124-130.

18. Orchard J, Seward H. Epidemiology of injuries in the Australian Football League, seasons 1997-2000. Br J Sports Med. 2002;36:39-44.

19. Malliaropoulos N, Isinkaye T, Tsitas K, Mafulli N. Re-injury after acute posterior thigh muscle injuries in elite track and field athletes. Am J Sports Med. 2011;39:304-310.

20. Wangensteen A, Bahr R, Van Linshoten R, et al. MRI appearance dose not change in the first 7 days after acute hamstring injury: a prospective study. Br J Sports Med. Epub 2016 Dec 28.

21. Koulouris G, Connel DA, Brukner P, Schneider-Kolsky M. Magnetic resonance imaging parameters for assessing risk of recurrent hamstring injuries in elite athletes. Am J Sports Med 2007;35:1500-1506.

22. Harris JD, Griesser MJ, Best TM, Ellis TJ. Treatment of proximal hamstring ruptures: a systematic review. Int J Sports Med. 2011;32: 490-495.

23. Gibbs N, Cross T, Cameron M, Houang M. The accuracy of MRI in predicting recovery and recurrence on acute grade one hamstring muscle strains within the season in Australian Rules football players. J Sci Med Sport. 2004;7:248-258.

24. Moen MH, Reurink G, Weir A, Tol JL, Maas M, Goudswaard GJ. Predicting return to play after hamstring injuries. Br J Sports Med. 2014;48(18):1358-1363.

25. Reurink G, Goudswaard G, Tol J, et al. MRI observations at return to play of clinically recovered hamstring injuries. Br J Sports Med. 2014;48: 1370-1376.

26. Reurink G, Almousa E, Goudswaard G, et al. No association between fibrosis on magnetic resonance imaging at return to play and hamstring re-injury risk. Am J Sports Med. 2015;43:1228-1234.
Open Access Journal of Sports Medicine

\section{Publish your work in this journal}

The Open Access Journal of Sports Medicine is an international, peer-reviewed, open access journal publishing original research, reports, reviews and commentaries on all areas of sports medicine. The journal is included on PubMed. The manuscript management system is completely online and includes a very quick and fair

\section{Dovepress}

peer-review system. Visit http://www.dovepress.com/testimonials.php to read real quotes from published authors. 